\title{
The Role and Need for Space-Based Forest Biomass-Related Measurements in Environmental Management and Policy
}

\author{
Martin Herold, et al. [full author details at the end of the article]
}

Received: 16 July 2018 / Accepted: 14 January 2019 / Published online: 11 February 2019

(c) The Author(s) 2019

\begin{abstract}
The achievement of international goals and national commitments related to forest conservation and management, climate change, and sustainable development requires credible, accurate, and reliable monitoring of stocks and changes in forest biomass and carbon. Most prominently, the Paris Agreement on Climate Change and the United Nations' Sustainable Development Goals in particular require data on biomass to monitor progress. Unprecedented opportunities to provide forest biomass data are created by a series of upcoming space-based missions, many of which provide open data targeted at large areas and better spatial resolution biomass monitoring than has previously been achieved. We assess various policy needs for biomass data and recommend a long-term collaborative effort among forest biomass data producers and users to meet these needs. A gap remains, however, between what can be achieved in the research domain and what is required to support policy making and meet reporting requirements. There is no single biomass dataset that serves all users in terms of definition and type of biomass measurement, geographic area, and uncertainty requirements, and whether there is need for the most recent up-to-date biomass estimate or a long-term biomass trend. The research and user communities should embrace the potential strength of the multitude of upcoming missions in combination to provide for these varying needs and to ensure continuity for long-term data provision which one-off research missions cannot provide. International coordination bodies such as Global Forest Observations Initiative (GFOI), Committee on Earth Observation Satellites (CEOS), and Global Observation of Forest Cover and Land Dynamics (GOFC-GOLD) will be integral in addressing these issues in a way that fulfils these needs in a timely fashion. Further coordination work should particularly look into how space-based data can be better linked with field reference data sources such as forest plot networks, and there is also a need to ensure that reference data cover a range of forest types, management regimes, and disturbance regimes worldwide.
\end{abstract}

Keywords Remote sensing $\cdot$ Climate change $\cdot$ Carbon stocks $\cdot$ Reducing emissions from deforestation and forest degradation (REDD) - Sustainable Development Goals (SDGs)

\section{Introduction}

Vegetation biomass and its dynamics are key components of the global carbon cycle, and central to provision of food and fibre worldwide. Living biomass in the terrestrial biosphere contains 450-650 PgC (Prentice et al. 2001), which is approximately $30 \%$ of the 
terrestrial carbon pool, since dead organic matter in litter and soils contains 1500-2400 $\mathrm{PgC}$ (Batjes 1996). The land sink, defined as uptake of carbon in mainly biomass and soils on land, was estimated to be $3.0 \pm 0.8 \mathrm{PgCyr}^{-1}$ between 2005 and 2014. To put this into perspective, this is similar to the growth in carbon in the atmosphere which was $4.4 \pm 0.1$ $\mathrm{GtCyr}^{-1}$ (Le Quéré et al. 2015). The link between vegetation biomass and the carbon cycle (Houghton et al. 2009) makes management of forest biomass relevant to the challenge of limiting global warming to $2{ }^{\circ} \mathrm{C}$, an internationally agreed target (UNFCCC 2015).

The change in quantity of biomass impacts the climate in three ways. First, the land sector currently represents the largest negative emissions potential (Griscom et al. 2017), mainly through sequestration of carbon in vegetation but also soils [with options such as carbon capture and storage being only currently operational at relatively small scales and with high marginal abatement costs (Irlam 2017)]. Second, disturbances (including fire), biomass losses (for example, forest degradation), and decomposition of the biomass result in carbon dioxide and other greenhouse gas (GHG) emissions. The anthropogenic impact on biomass is significant and represents approximately $23.8 \%$ of the global potential net primary productivity which is $15.6 \mathrm{PgCyr}^{-1}$ (Haberl et al. 2007). Third, the presence of woody biomass influences climate by modifying water and energy exchanges with the atmosphere, thus influencing local hydroclimates (Lorenz and Pitman 2014; Zomer et al. 2016; Ellison et al. 2017). Vegetative biomass is also a key component of many of the world's ecosystems and represents habitats which support biodiversity and provide resources for human use. In addition, many communities rely on the resources found in forests and other ecosystems for food, fuel, and fibre, all of which are biomass components (Hermans-Neumann et al. 2016). Related to this, the estimation of biomass is important for quantifying and understanding the impacts of dynamic land use or land-cover events such as encroachment of vegetation and removal of biomass. Additionally, this information is useful for estimating the likelihood and impact of fire, for monitoring plantation dynamics and forest management practices, and for assessing resources for wood products and bioenergy.

Accurate information on biomass distributions and on the spatial and temporal dynamics of biomass change is therefore essential to plan adaptation and mitigation actions in the land use sector. Progress on domestic policies in the land use sector can be assessed with biomass data, which must meet the reporting needs of international policies, for example the Paris Climate Agreement (UNFCCC 2015). These include the Nationally Determined Contributions and regular global stocktakes which countries contribute to, and which represent a country's proposed contribution to achieving the goals of the United Nations Framework Convention on Climate Change (UNFCCC).

Knowledge of the distribution of biomass across the globe is limited, and consistent data on changes over time at both the global and regional levels are even less available. At the same time, there is a proliferation of biomass mapping efforts based on airborne and space-based data. In this paper, we focus estimates based on space-based data, which are often calibrated and validated using field data, including remote sensing such as terrestrial lidar and also airborne data. From a space-based perspective, both optical and radar (Synthetic Aperture Radar (SAR)) data can be useful for biomass mapping. Radarbased measurements, however, have larger sensitivity to forest biomass than optical systems, in particular, when they are combined with Light Detection and Ranging (lidar) (Asner et al. 2011; Mitchell et al. 2017). It is important to clarify that remote sensing cannot provide direct biomass measurements, but provides information from which biomass can be estimated. Long wavelength (L-band) radar and lidar sensors have been commonly used to estimate forest height and structure and aboveground biomass (AGB). Multiple 
large-geographical-scale AGB maps with coarse spatial resolution $(>500 \mathrm{~m}$ ) have been produced using space-based lidar data from the Geoscience Laser Altimeter System (GLAS) (Baccini et al. 2012; Saatchi et al. 2011). Biomass maps at $30 \mathrm{~m}$ or finer resolution have also been produced; however, space-based maps typically have low accuracy because of different forest structures (e.g., heights, allocations of AGB) and varying environmental conditions (e.g., inconsistent estimates between frozen and unfrozen conditions) (Lucas et al. 2015). An additional challenge is that existing continental-to-global-scale maps are based on data from sensors which are no longer operational (GCOS 2016). Such maps remain one-time efforts lacking long-term continuity and are made available as independent products by the scientific community. These products mainly provide a snapshot of biomass at one moment in time (or are produced from composites of various timeframes) and do not provide information on changes over time. This does not fulfil user needs related to information on biomass changes, and the proliferation of maps confuses end users over which map to use for specific purposes and why.

Efforts including JAXA's L-band radar missions (JERS-1, ALOS, ALOS-2) and NASA's Geoscience Laser Altimeter System (GLAS) mission onboard the Ice, Cloud, and land Elevation Satellite (ICESat) have for the past two decades constituted the main testing grounds for space-based methodology development for AGB estimation. There are now concrete plans, however, for a new generation space-based missions using long wavelength L- and P-band radar and lidar targeted at forest AGB mapping and estimation specifically, including many which have an open data policy (Fig. 1). In this figure, the lifetime of radar satellites/space-based missions where not fixed/known has been estimated to be 5 years, although may be much longer, and advanced non-commercial missions only were included. Where the end date was not known, the date is in grey. Tandem-L is a phase A study and thus is not confirmed. These missions overlap in terms of their objectives and their intended times of operation and thus have potential to close the gap for data and information needed to stimulate activities and report progress on many forest-related policy and management applications.

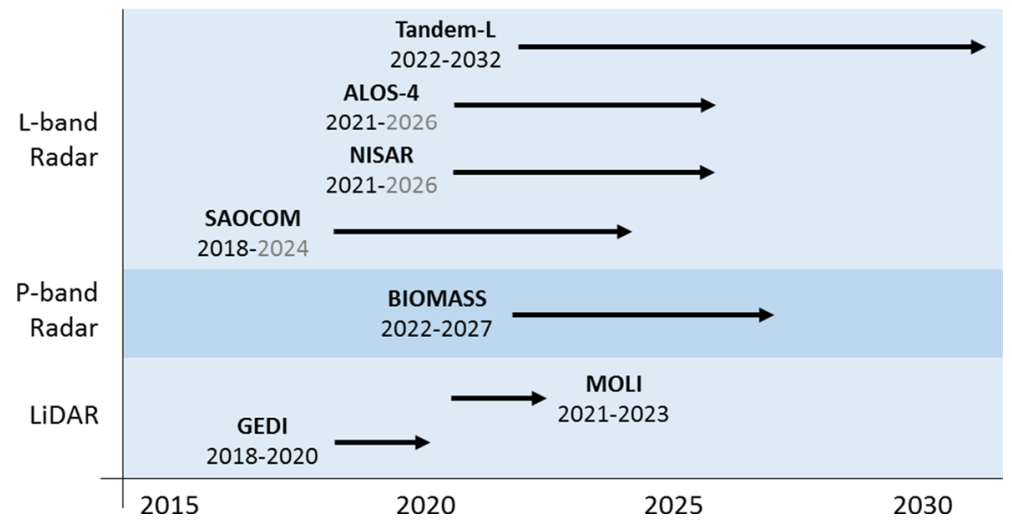

Fig. 1 Near-future space-based missions with an open data policy, where one of the key mission goals is biomass monitoring. ALOS (Advanced Land Observation Satellite); NISAR (NASA-ISRO Synthetic Aperture Radar); SAOCOM (Satélite Argentino de Observación Con Microondas) (A, 2018, and B, 2019); GEDI (Global Ecosystems Dynamics Investigation Lidar); MOLI (Multi-footprint Observation Lidar and Imager) 
With the future space-based biomass monitoring on the horizon, there is need to summarize and consolidate the role of and needs for biomass information based on data from these missions. To this end, our assessment:

1. Identifies and describes the requirements of biomass data for key policy and forest management processes;

2. Synthesizes the requirements and assesses the key gaps for policy (and forest management processes), considering the availability and experiences with large scale biomass products;

3. Derives recommendations which aim to bridge the gaps identified by better aligning various space-based biomass mapping efforts to serve these policy and management processes.

\section{Requirements}

\subsection{Defining Biomass}

Different definitions of biomass are used for different applications. Biomass of terrestrial ecosystems is recognized in major documents including IPCC (2003, 2006), Tompo et al. (2010), Baede et al. (2007), and FAO (2015) as broadly the mass of live and dead organic matter. Biomass can be divided into AGB and belowground biomass (BGB), and live and dead biomass; however, classification schemes vary (GlobBiomass 2017). BGB is typically defined as living root biomass, although fine roots (for example, $<2 \mathrm{~mm}$ ) are sometimes excluded (IPCC 2003). AGB is defined as all living biomass above the soil (IPCC 2003). In other definitions, deadwood and other organic material (litter) which are lying above the soil are included in the definition of AGB, but deadwood and litter which are in the soil are not (GlobBiomass 2017). Material laying above the soil may be in various states of decomposition, and the Intergovernmental Panel on Climate Change (IPCC) classification guidance requires the live and dead biomass pools to be counted separately, which can cause some difficulties, for example, stumps can be part of both living and dead wood.

Biomass is measured in units of mass of dry weight, or of carbon (GlobBiomass 2017), which is conventionally converted from dry weight with a factor of 0.47-0.5 (IPCC 2006). Biomass regularly refers to density of biomass, e.g., amount of biomass per unit area (in this paper, hereafter referred to as biomass). Biomass in the various pools can be estimated through established field methods, however, from the perspective of space data, typically only AGB is estimated. Other carbon pools cannot be operationally estimated from spacebased data, although different properties of biomass can be predicted using information from different space-based sensors, giving some information about other carbon pools. In general, space data may not be sufficient for users who require information about the other biomass pools.

Figure 2 shows a forest biomass classification system, which can also be used in other ecosystems. Often the classes are related to the reporting needs of different policies and can vary for different observations/products in terms of including live and/or dead biomass, or the division of various vegetation compartments (woody, branches, and leaves). A clear and transparent definition of biomass should be provided with each measurement/product, to ensure that multiple types of measurements and estimations are used consistently and correctly. 


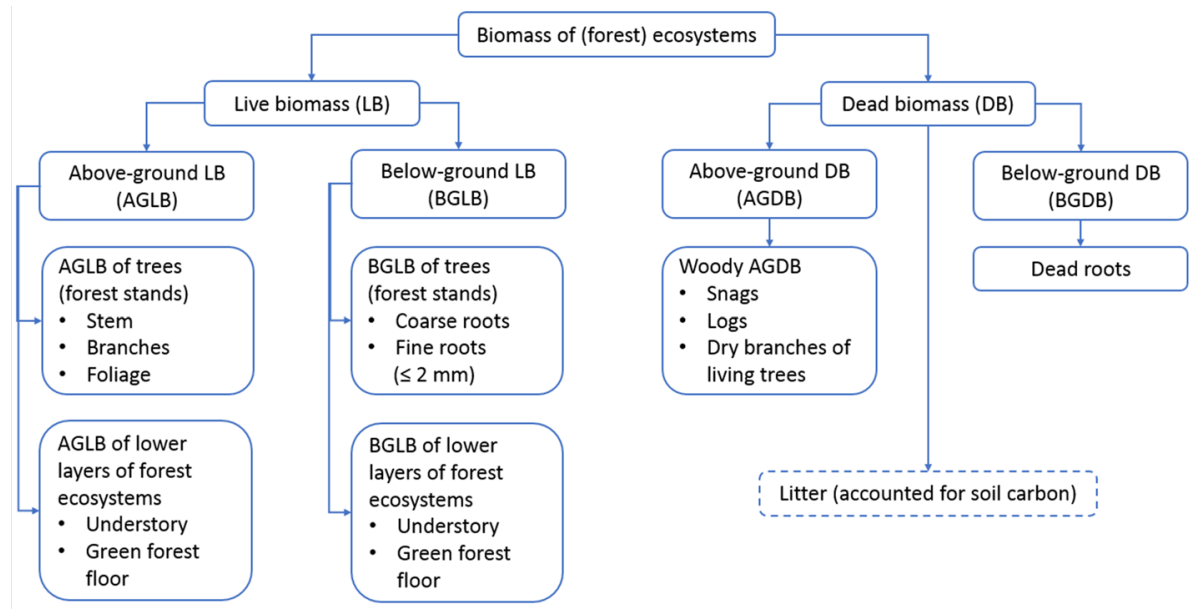

Fig. 2 Classification scheme for biomass in forest ecosystems adapted from GlobBiomass (2017)

\subsection{Users and Their Needs}

Multiple international policies that require biomass information have been developed and adopted in recent years. Multilateral agreements include performance-based incentive systems to curb trends in forest loss in the tropics and to stimulate reforestation and forest restoration, and to enhance the goods and services provided by forests. Most prominently, international negotiations related to climate change led to increased interest in monitoring forest biomass using space-based data (Kumar and Mutanga 2017). Voluntary international processes and their targets related to forests will require biomass data to track the achievement of their goals. These processes include the United Nations Forum on Forests, the Aichi targets under the UN convention on Biological Diversity which includes at least halving the loss of all natural habitats, the 2011 Bonn Challenge to restore 150 million hectares of degraded land by 2020, the 2014 New York Declaration with several targets of reduction in loss of natural forest, the land degradation neutrality target under the UN Convention to Combat Desertification, the UNFCCC NDCs, and the related Sustainable Development Goals (SDGs). Other agreements such as the Committee on Food Security could also benefit from biomass information that could be related to crop and pasture productivity. We explore five key national and international policies, commitments, and agreements in more detail.

\subsubsection{Estimating Aboveground Biomass as an Essential Climate Variable}

Essential Climate Variables (ECVs) are observable physical, chemical, or biological variables which can be important to characterize the Earth's climate system (GCOS 2010). Users of ECV products include global, regional, and national groups such as climate and integrated assessment modellers, World Meteorological Organization, national meteorological services, and others that require consistent products over large areas. These ECVs have been identified by the Climate Change Convention (UNFCCC) under its agenda item on research and systematic observations (under the leadership of the Global Climate Observing System (GCOS)) and include AGB (ECV T12). Other ECVs are also impacted 
by changes to ECV T12, including Albedo (ECV T8), Land Cover (ECV T9), FAPAR (Fraction of Absorbed Photosynthetically Active Radiation, ECV T10), LAI (Leaf Area Index, ECV T11), and fire disturbance (ECV T13) (GCOS 2010). To monitor ECV T12, GCOS proposed the development of gridded AGB datasets (GCOS 2015). Specifically GCOS highlights the further need for actions to:

1. Encourage inter-agency collaboration on developing methods to combine biomass estimates from current and upcoming missions (GCOS Action: 52);

2. Encourage inter-agency collaboration to develop validation methodologies (GCOS action 53)

3. Develop a set of validation sites covering the major forest types, particularly in the tropics (GCOS action 54);

4. Promote access to well-calibrated and validated regional- and national-scale biomass maps including uncertainty assessment (GCOS action 55);

5. Improve access to high-quality forest inventories, especially in the tropics, which can be used for research purposes and Reducing emissions from deforestation and forest degradation plus (REDD+) (GCOS action 56)

GCOS has recently updated the more specific requirements for estimating AGB as ECV [see also Global Observing Systems Information Center (GOSIC) (GCOS 2016; WMO 2018)]. In the context of ECVs, AGB is generally defined as the mass of live organic matter above the soil in terrestrial vegetation, thus excluding roots, litter, and dead wood (GCOS 2016). ECV AGB is quantified in mass of dry weight in metric tons. Biomass is quantified in $\mathrm{g} \mathrm{m}^{-2}$ (dry matter) or multipliers (e.g., $\mathrm{Mg} \mathrm{ha}^{-1}$ ). There are multiple uncertainty metrics for biomass estimates, which include the relative and absolute systematic deviation and confidence interval or root-mean-square error (RMSE) for the overall biomass estimate and for each biomass class/range which can be estimated from reference data of better quality. RMSE alone is not a strong indicator of uncertainty since it mixes systematic deviation and precision. Systematic deviation is often the most significant error and varies among biomass ranges. Ideally, an error distribution as a function of biomass should be provided, but is rarely achieved in practice. As a minimum, a comparison of the ECV product with independent (in situ) reference data should provide uncertainty related to systematic deviation and precision among multiple biomass class/ranges in per cent (for relative) and $\mathrm{Mg} \mathrm{ha}^{-1}$ (for absolute).

GCOS additionally asks for consideration of stability, which is to reflect the change in uncertainty over time (GCOS 2016). The metric and units for stability are the same as for uncertainty characterization and include the relative and absolute error assessments and confidence interval or RMSE, overall and by biomass class/range estimated using multidate reference data of better quality. The stability requirements are more important than for overall uncertainty since the aim for multi-date ECV data is to provide information on biomass changes, and stability needs to be greater to actually be assessed. Since biomass varies in space, when moving to more detailed spatial resolutions, this variability quickly becomes large. This makes it very hard to estimate accurately when using multiple observation sources (which may have different spatial and temporal resolutions), especially for natural and tropical forests. The current GCOS suggestion is a horizontal resolution of 0.25 ha $(50 \mathrm{~m} \times 50 \mathrm{~m}$ resolution) outside the (sub-) tropics and about 1 ha $(100 \mathrm{~m} \times 100 \mathrm{~m})$ for tropical forests. ECV biomass products should move beyond just being 
one-time products and ideally be provided annually or at least every 5 years to capture the most important changes.

\subsubsection{National GHG Reporting Needs in the Context of the UNFCCC}

Biomass measurements are of particular significance for policies related to the UNFCCC, because countries must monitor emissions related to gains and loss of biomass, and must report on these regularly (Herold and Johns 2007). Data and information on forest biomass stocks are not only required for international information/data needs, but also for national needs to support national policy formulation and mitigation activities.

Guidelines for reporting emissions and removals on the national level are provided by the IPCC Good Practice Guidance (GPG) and guidelines (GL), which countries use when reporting through their GHG inventories or other reporting avenues to the UNFCCC. A refinement of the 2006 IPCC GL (IPCC 2006) is ongoing with a planned release for 2019 and will be the first update of the Agriculture, Forestry and Other Land Use (AFOLU) guidelines since 2006. Updates will include additional information on tropical and subtropical forest biomass factors, as a result of recent efforts by REDD+ countries, and more information on the role of space-based data in biomass monitoring. More specifically, the guidelines will include a new section introducing the use of biomass estimates from maps estimated from space-based data. The use of biomass maps is increasingly important, since these wall-to-wall datasets have the potential to complement plot-based biomass measurements available through national forest inventories (NFIs). The characteristics and usefulness of biomass maps produced using space data for national GHG inventories depend on multiple factors:

1. The definitions for forest and biomass or AGB used to produce the map and how this definition relates to the one used in the national GHG inventory;

2. The type of space-based data sources in terms of spatial resolution, temporal coverage, and the degree to which the signal responds, or is sensitive to AGB;

3. The method used to construct the map. Methods can range from simple interpolation of field estimates of biomass using spatial covariates to more complex modelling of AGB using field estimates and observed space-based data signals (Goetz et al. 2009; Avitabile et al. 2011);

4. The availability and reliability of biomass-related field data, which are of better quality than the map and are needed to produce and validate the biomass map;

5. The degree to which map uncertainty is characterized and the manner in which it is used to assess systematic deviation and precision for large-area estimates in support of national GHG inventories.

With these factors in mind, biomass maps can improve the stratification of field-based biomass inventories, increase data in under-sampled or inaccessible areas, and serve as an independent data source for verification purposes (provided that the field data were not used to calibrate the biomass maps used).

In general, net carbon emissions from land use change are estimated by multiplying activity data (area of change) by an emission factor or removal factor (the carbon stock change per unit of change) (IPCC 2006). In this respect, the use of biomass maps for the estimation of carbon emissions at IPCC Tier 2 and Tier 3 levels can be achieved in three 
ways. First, biomass maps can provide the base to estimate carbon stocks. Such analyses require consistency among the activity data and biomass maps concerning definitions, geolocation, and spatial and temporal characteristics. The use of regionally aggregated carbon stocks (e.g., using average estimates for different forest types) helps to reduce inherent pixel-level uncertainties in biomass map data for national-scale estimations. Countries have used this approach to increase data density in areas under-sampled by field inventories. Second, biomass change and carbon emissions can be estimated directly from multidate biomass maps. This approach provides an assessment of carbon stock changes in AGB from land use change and, in particular, also includes changes within forests remaining forests such as degradation and regrowth, management and harvest, and natural disturbances. This method requires consistent and well-calibrated biomass maps using field measured and space-based data to accurately estimate biomass changes and a quality requirement that has so far not been achieved for national GHG inventories. Improvements in both the field estimates of biomass change and remote sensing technologies in the coming years could lead to such approaches becoming efficient and accurate for GHG inventory purposes. Third, biomass maps can be integrated with remote sensing-assisted time series of land use change and/or with IPCC Tier 3 models to estimate emissions. This way, the biomass map data can be linked to land use to better reflect the complexity of forest-related carbon fluxes. A critical element of this type of application is the consistency among the various data sources and models concerning definitions (e.g., forest, biomass pools) and spatial and temporal data characteristics. Map unit prediction uncertainties in biomass maps propagate to larger area estimates and can lead to substantial uncertainties in national emissions estimation if not properly considered, particularly in relation to the effect of spatial autocorrelation. The application of these three approaches requires maps which are well-calibrated for national circumstances (McRoberts et al. 2019). Many available large-area biomass maps might not be consistent with national definitions of forest and/or biomass pools and often exhibit large systematic deviation in the estimation of carbon stock and changes for national and local assessments (Avitabile et al. 2016).

Incorporating biomass maps in national GHG inventory efforts requires a long-term perspective, such as establishing a data protocol to assure accessible data in the future. Comparability across timescales is essential to meet the IPCC guidance for consistency. Developing countries in particular have been making significant progress in using spacebased data for providing activity data and national forest inventories for estimating emission factors (Romijn et al. 2015). These increasing capacities should help the potential uptake of novel biomass mapping and estimation possibilities by countries but so far few examples exist; additional national-scale efforts are needed to demonstrate that potential.

\subsubsection{Result-Based Schemes Including Multilateral, Bilateral, and Project-Based Voluntary Initiatives}

Efforts to reduce emissions from deforestation and degradation, sustainably manage forests, and conserve and enhance forest carbon stocks (REDD+) in developing countries have been moving into accessing result-based payments (third REDD+ phase), which requires robust and credible systems for measuring, reporting, and verification (MRV). REDD+ efforts have been re-enforced as one of the mitigation foci of the Paris Agreement (UNFCCC 2015; Turnhout et al. 2017). The result-based nature of REDD + requires that GHG emissions and removals related to REDD+ activities are benchmarked against a reference level to estimate their impact in units of $\mathrm{tCO}_{2}$ equivalent. In many cases, emissions 
are estimated using activity data or land use change area (e.g., forest cover gain or loss) and an emissions factor, which is essentially the carbon stock or biomass of the forest. Biomass maps offer opportunities to not just look at loss or gain in the context of forests, but to look at change which can occur to varying degrees (for example, in the case of degradation or regrowth). Reporting under REDD+ frameworks is very much related to national GHG inventories; however, the objectives and requirements vary across frameworks, as outlined in Table 1.

REDD+ readiness efforts have triggered significant investments in improving developing countries' technical and institutional capacity for forest monitoring, including the capacity to utilize space-based data and remote sensing technologies which are seen as cost-effective methods. These investments and interest have spurred the forest observation community to develop new data sources through targeted research and methods (see, for example, http://www.gfoi.org/rd/), provide justification for space missions (including those for forest biomass), and develop improved guidance (GOFC-GOLD 2016).

\subsubsection{Sustainable Development Goals}

The SDGs, adopted by the UN in 2015 , have 17 goals aimed at sustainably transforming our world (UN 2016). There are 232 targets, each with one or more indicators which must be monitored (UN 2017). New geospatial data and technologies are expected to be crucial for a number of the indicators. In particular, biomass data are essential for monitoring Goal 13 (Climate action) and Goal 15 (Life on land) (Romijn et al. 2016). Specifically, indicators 15.2.1 Forest cover under sustainable forest management, 15.2.2 Net permanent forest loss, and 15.3.1 Percentage of land that is degraded over total land area require forest biomass data. Several other targets could potentially use biomass data, for example goal 2.3 related to doubling agricultural productivity by 2030 could utilize biomass data for indicator 2.3.2 Total Factor Productivity. Likewise, indicator 7.2.1 Renewable energy share in the total final energy consumption could also include information on biomass for bioenergy in plantations. SDGs are typically set per country; however, spatial differences within a country can be more adequately monitored using space-based data, thus giving information on the extent to which SDG targets are being met at the sub-national level. The time frame for annual reporting on the SDG indicators is 2015-2030.

\subsubsection{Local Forest and Land Management}

Forest monitoring at the local level can serve many purposes, including to monitor tree growth and wood production in commercial operations including bioenergy production, to monitor illegal activities, such as illegal logging and illegal charcoal production, to provide information for the monitoring and reporting requirements related to sustainable timber certification, and to provide data on land use which can inform sustainable landscape management planning. Sustainable management plans may include fire prevention plans to inform forest laws and strategies. Balancing different utilities that forests can provide — both market goods and services and non-market goods-require, however, more comprehensive data that go beyond pure biomass information. In addition, biomass data are typically required at relatively small (sub-national) spatial scales, and with fine resolution, to capture details and subtle changes in the landscape. For this reason, airborne and field measured biomass data are often typically more suitable than space-based data. However, space-based information could be a useful data source if it can provide timely data at 
Table 1 Various REDD+-related reporting fora, their purpose, and considerations of uncertainties

\begin{tabular}{|c|c|c|}
\hline Context & Purpose & Requirements/consideration of uncertainties \\
\hline $\begin{array}{l}\text { REDD+-related } \\
\text { submissions and } \\
\text { National GHG } \\
\text { inventories to } \\
\text { UNFCCC }\end{array}$ & $\begin{array}{l}\text { Regular reporting required at } \\
\text { the national level, REDD+ } \\
\text { reports, in developing } \\
\text { countries in the context of } \\
\text { result-based finance, and } \\
\text { biennial update reports } \\
\text { (BURs) for all countries }\end{array}$ & $\begin{array}{l}\text { Key GHG source categories should be reported on } \\
\text { Tier } 2 \text { level (using national emissions factors) in the } \\
\text { national GHG Inventory. REDD+ FREL/FRLs, and } \\
\text { REDD+ Annexes to the BURs are assessed through } \\
\text { specific technical assessments and reviews by UNF- } \\
\text { CCC roster of experts. The stepwise approach allows } \\
\text { continuous improvements including uncertainty }\end{array}$ \\
\hline $\begin{array}{l}\text { Green Climate Fund } \\
\text { (GCF) }\end{array}$ & $\begin{array}{l}\text { Finance for forest transfor- } \\
\text { mation for climate change } \\
\text { mitigation and adaptation. } \\
\text { Result-based payments for } \\
\text { REDD+ }\end{array}$ & $\begin{array}{l}\text { In the case of result-based payments for REDD+, } \\
\text { these are based on the UNFCCC Technical Assess- } \\
\text { ment and Technical Reviews and a further assess- } \\
\text { ment through a score card where uncertainty is part } \\
\text { of the scoring system to allocate payments }\end{array}$ \\
\hline $\begin{array}{l}\text { Forest Carbon } \\
\text { Partnership Facil- } \\
\text { ity's Carbon Fund } \\
\text { (FCPF CF) }\end{array}$ & $\begin{array}{l}\text { Pilot market transactions for } \\
\text { REDD+ }\end{array}$ & $\begin{array}{l}\text { An IPCC Tier } 2 \text { is required to estimate emissions and } \\
\text { removals. Uncertainty needs to be assessed and } \\
\text { reported. Verification of emission reductions by an } \\
\text { independent third party. Potential discount based on } \\
\text { overall uncertainty of reported and verified emission } \\
\text { reductions }\end{array}$ \\
\hline $\begin{array}{l}\text { Other initiatives } \\
\text { (e.g. Verified Car- } \\
\text { bon Standard) }\end{array}$ & $\begin{array}{l}\text { Issuance of emission reduc- } \\
\text { tion units for compliance } \\
\text { and/or non-compliance } \\
\text { carbon market }\end{array}$ & $\begin{array}{l}\text { Varies by standard, but uncertainties should be } \\
\text { assessed and considered. Independent verification } \\
\text { is often part of the process. Often a preference for } \\
\text { conservative approaches }\end{array}$ \\
\hline
\end{tabular}

fine resolutions. Space-based data can also be combined with field or airborne data, from NFIs for example, to upscale the data across larger areas. Currently, several space-based monitoring systems provide early warnings on forest disturbance, such as illegal activities (Hansen et al. 2016); this information can be combined with biomass maps to determine whether forest loss is occurring in high biomass forests, which are typically high biodiversity areas, and are therefore valuable habitats which be prioritized for protection.

\subsection{Transparency and Broader Stakeholder Engagements}

Enhancing transparency is fundamental to realize the bottom-up nature of the Paris Agreement, and should be understood as catalyst for action by providing, in the context of biomass data, open and consistent time series, transparent definitions, and assumptions and methodologies that will enhance the credibility and reliability of land use sector mitigation activities (Carter et al. 2018a) in both developing and developed countries. Transparency is already one of the principles of the IPCC guidance for GHG inventories together with accuracy, completeness, comparability, and consistency (UNFCCC 2003). Open and transparent estimations are also required in cases where results have to be assessed and verified. This includes publicly available input data sources, and the full transparency of methods, including algorithms. This builds public trust in reported results and encourages cooperation among multiple stakeholders including the collaborative design of interventions.

To better understand the user needs, a survey was undertaken with the aim of assessing stakeholders' data needs when monitoring GHG emissions in the land use sector (Romijn et al. 2018). A total of 557 answered the questionnaire and provided information on the type of organization for whom they were working. The survey results show 
that current open and freely available biomass datasets are not able to fulfil all stakeholder needs completely. Users were found to require detailed documentation regarding the scope and usability of the data (97\% of all survey respondents), data sources which are comparable with alternatives, uncertainty estimates for evaluating mitigation options (94\% of all survey respondents), more region-specific data with greater accuracy and detail for sub-national application, and regular updates and continuity for establishing consistent time series (83\% of all respondents) (Romijn et al. 2018). Specifically, on biomass data needs, the survey asked different user groups their desired different levels of accuracy in terms of IPCC Tiers (Fig. 3). Responses are divided into groups, and ALL relates to all respondents, including the other groups, such as "local stakeholders", "donor organizations", "intergovernmental organizations", and others. Developing country governments include Non-Annex 1 governments, and developed country governments include Annex-1 governments according to the UNFCCC definition. "Research" includes universities and research institutes, and non-governmental organizations (NGO) include International (I) NGOs. Tier 1 emission factors are default values for broad continental forest types, e.g., from IPCC Emission Factor Data Base, Tier 2 emission factors are country specific data for key factors, e.g., from field inventories, permanent plots, and Tier 3 emission factors are based on detailed national inventory of key $\mathrm{C}$ stocks, comprehensive field sampling repeated at regular time intervals, soils data, and use of locally calibrated models. The government groups all selected Tier 2 or Tier 3, with Annex 1 (developed) country experts selecting Tier 3 (74\%), even more so than the research community. The NGO community selected Tier 1 information (20\%). On average, $43 \%$ of respondents selected Tier 3 , while $47 \%$ of respondents selected Tier 2.

Multiple datasets are available which can be used by stakeholders to estimate biomass (Fig. 4). The datasets in Fig. 4 are IPCC (2003, 2006), Baccini et al. (2012), Saatchi et al. (2011), Harris et al. (2012). The bars show the proportion of respondents who were aware of the dataset and the proportion that both used it and found it "useful" or "very useful" when responding to the question "Was this dataset useful for your research and/or business purposes?" Other response options were "somewhat useful", "not very useful", and "not at all useful". Several differences were found in the awareness and usefulness of these datasets. While almost all stakeholders are aware and use the IPCC guidance, the knowledge and uptake of biomass maps were much less. This emphasized the current status that available maps are not used in GHG reporting by countries. There is a significant gap between stakeholders being aware of certain data sources and whether they actually found them useful for their purpose. This highlights the large divide between what is available and what is used. NGO respondents were more likely to be aware and users of these biomass datasets than other user groups.

Fig. 3 Desired level of IPCC Tiers. Amended from Romijn et al. (2018)

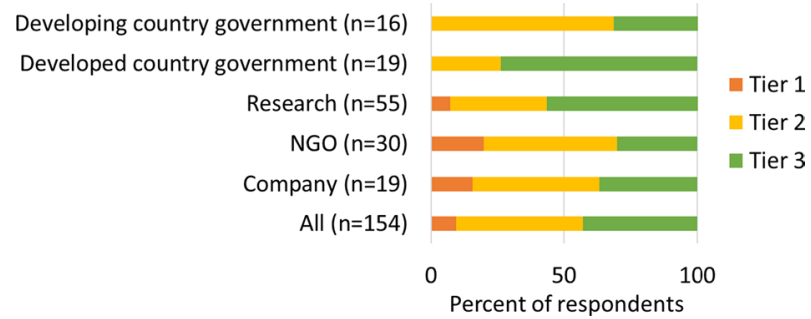




\section{Synthesis of User Needs and Gaps}

A summary of the key initiatives, user groups, and requirements for biomass mapping in Table 2 emphasizes that biomass data derived from space-based data are useful for multiple purposes from national to international reporting related to forest change, to monitoring climate variables and sustainability goals. Some stakeholders are already using biomass maps along with other biomass data sources for their monitoring and reporting needs and find these useful. In light of these requirements, several gaps remain, which might be potentially filled by future space-based missions and the availability of those data. These gaps are described, and opportunities discussed, before recommendations for the future of biomass mapping are made.

The gaps and barriers for the use of biomass estimates from biomass maps by environmental policy and management (Table 2) can be summarized as follows:

Insufficient Level of Detail: Different users related to different policy and management processes require different levels of detail in terms of:

- Spatial Resolution: from spatially explicit/stand-level information of less than one hectare to many kilometres for global vegetation models;

- Geographic Extent: ranging from a forest management unit to global scale;

- Temporal Coverage: some users prefer a particular year; some want data that are most recent (near-real-time information) or available for longer time series;

- Definition: there is variability in needs in terms of which vegetation components are considered and whether dead biomass is included or not.

Given that most available regional and global biomass maps are limited in their spatial resolution and temporal coverage, most of them have not been found suitable for many of the applications we have assessed here.

Biomass Maps Versus Change: Most regional and global biomass maps exist as onetime products. While there is value in and need for high-quality biomass stocks data, many applications require biomass change information. Although case studies exist (Næsset et al. 2013 , 2015), it is only recently that reports of estimation of biomass change over large

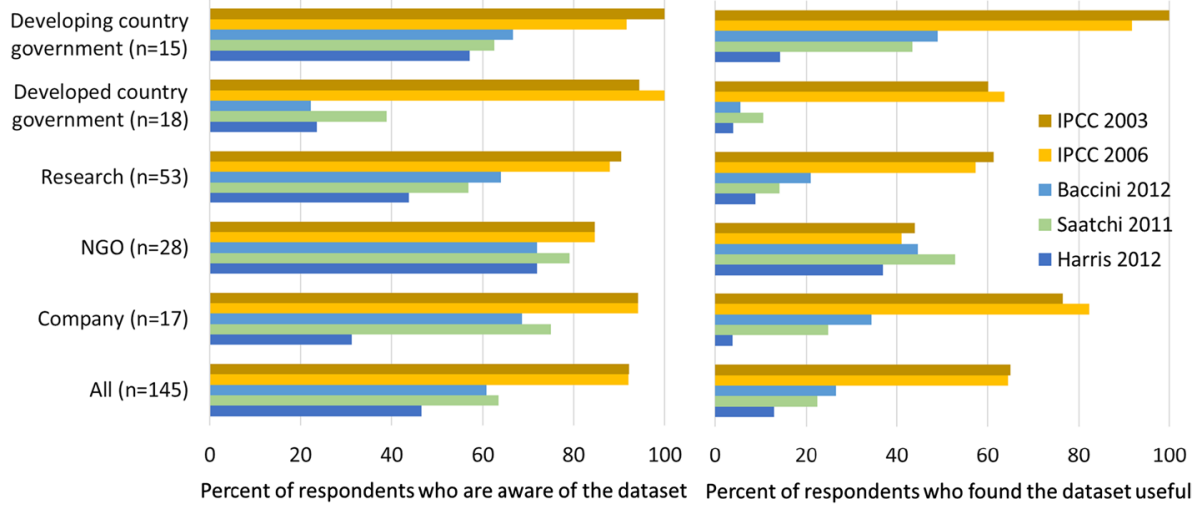

Fig. 4 The most frequently selected five datasets which the questionnaire respondents were aware of when asked "Are you aware of this dataset" and "Was this dataset useful for your research and/or business purposes?" 
areas from space-based data are starting to appear in the scientific literature (Baccini et al. 2017).

Conflicting Information: Urgency by researchers and scientists to improve space-based monitoring capabilities has naturally led to a diversification of methods, with positive implications in terms of innovation, and demonstrating the potential. Different datasets are available and often provide inconsistent information which confuses users. Identifying the sources of differences in these maps is difficult, due to lack of detailed descriptions/transparency, different definitions, temporal coverage, and also the lack of information on the uncertainty of the maps (Avitabile et al. 2016; Böttcher et al. 2017). Enhanced user's guidance on which data sources are most suitable for which purposes could be included in the upcoming 2006 IPCC GL refinement. The user should be provided with documentation of the product to understand which one to use for a certain purpose and why.

Limitations in the Complementary Use of Field/Airborne and Space Data: Biomass monitoring still suffers from the conceptual and technical divide between space-based data and traditional means of gathering biomass data (i.e. collecting data in the field). Highquality in situ data are needed for calibrating and validating space-based biomass maps, and the quality of this calibration or validation data must be higher than that of the map (Stehman 2009; GFOI 2016). But lack of in situ data in certain locations, use of different definitions of forests and biomass, and uncertainties in both field and space-based data have led to limited complementarity. Current biomass mapping from space is essentially disconnected from plot-based national forest inventory efforts (Böttcher et al. 2017).

Lack of Capacity of Key Stakeholders: One of the main barriers to progress in general and relating in particular to the uptake of space-based biomass derived data for biomass monitoring is the capacity of users such as country experts and non-technical experts to access and use the data. A study of countries' capacities to measure, monitor, and report on REDD+ found many to have low capacity, particularly in Africa (Romijn et al. 2012). Despite efforts to increase capacities, a capacity gap remains in many developing countries (Romijn et al. 2015) which continue to limit the uptake of new technologies. The use of biomass maps by key stakeholders is also hindered by the lack of capacity to understand the methods that were used to produce them.

Gaps Between Theoretical Opportunities and Policy and Management Praxis: An oftenoverlooked limitation of biomass and forest monitoring capabilities arises from a gap between what is needed by users, what has been successfully demonstrated in a research environment, and what can be developed and maintained in an operational environment, such as a country's National Forest Monitoring System. The technologies offered may not meet the user requirements or be practical for operational implementation, and an analysis of user requirements should be undertaken to ensure that what is offered can be adopted successfully. In particular, investments to develop new data sources and methods are significant and often do not consider how such novel approaches can be scaled geographically and then reliably maintained at a reasonable cost by users. This problem is often especially acute in countries with low technical capacity. Unclear institutional arrangements and turnover of technical staff can create problems for responding to new requirements and technical opportunities and for sustainability of monitoring efforts (Ochieng et al. 2016).

Uncertainty Characterization is Missing or Not Suited: Currently global maps are available, but using these datasets to estimate biomass at national scale does not meet the level of uncertainty required for REDD+ (Mitchell et al. 2017). Some do not provide adequate uncertainty estimates so these have to be estimated by the users, which can be difficult, and this process relies on assumptions and thus is uncertain in itself (Carter et al. 2018b). To add to the challenge, most biomass mapping accuracy varies by forest type and biomass 


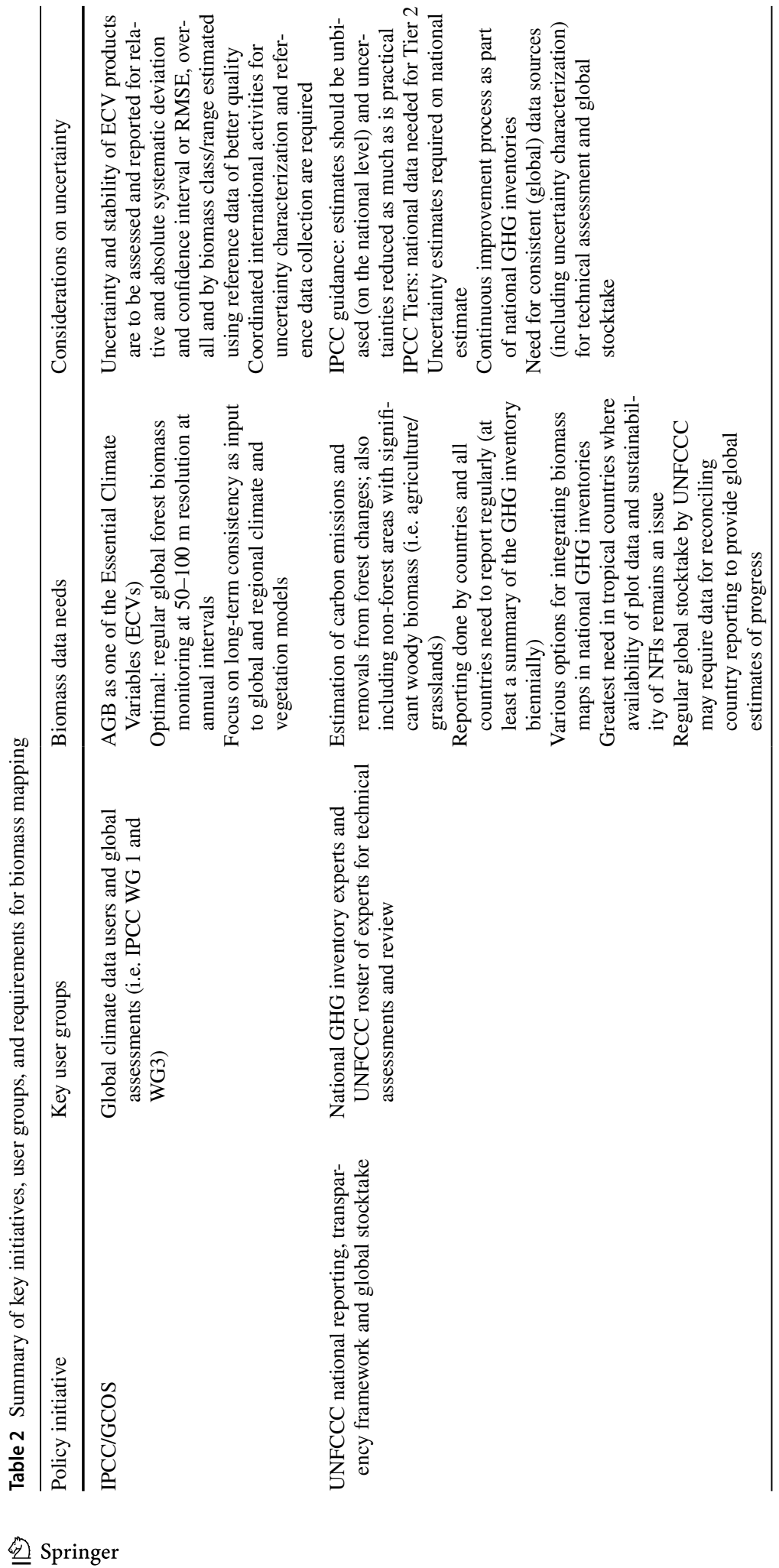




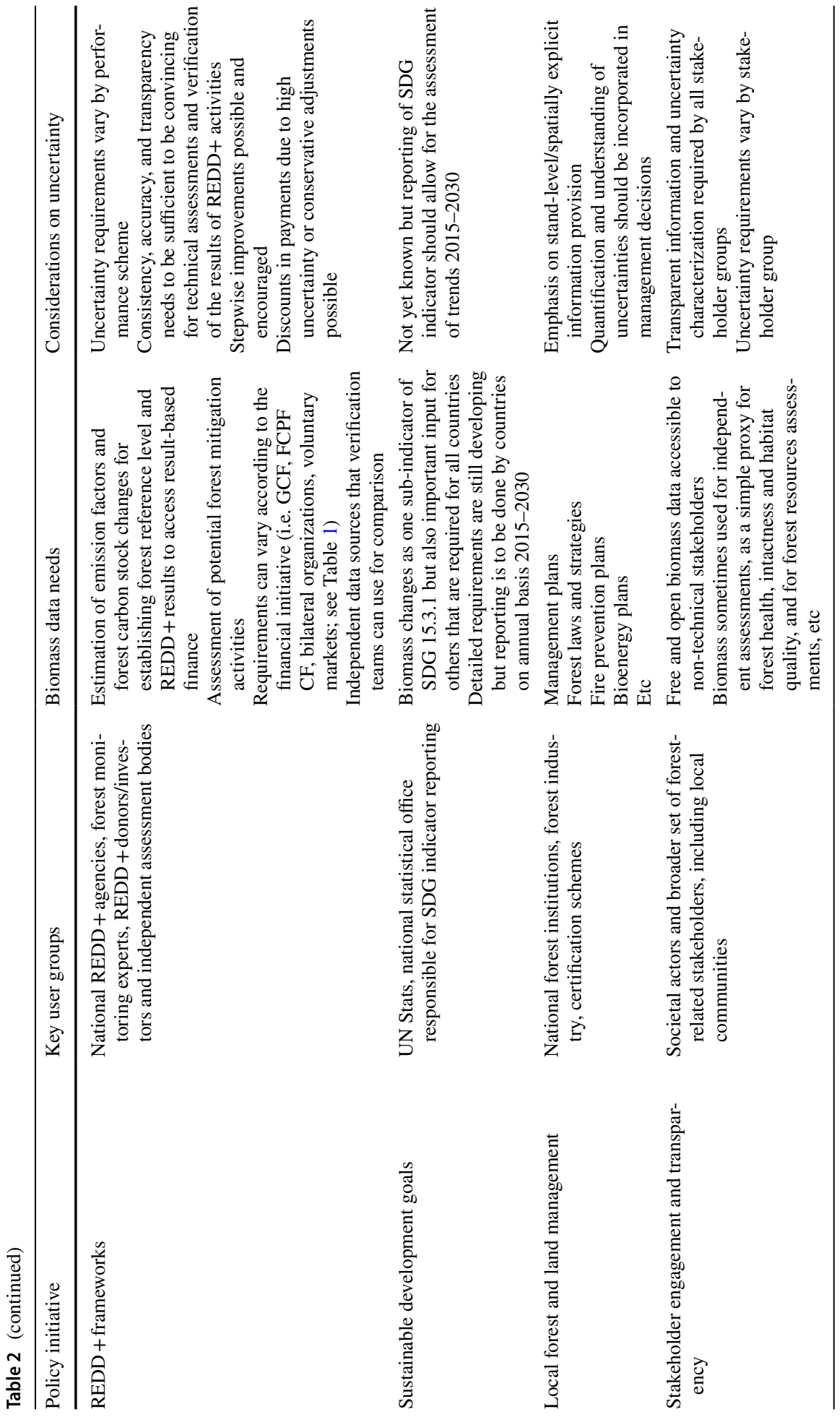


range. Biomass mapping typically performs poorly in high biomass and dry regions of the tropics, and uncertainties are particularly large there (Avitabile et al. 2016). Users have specific requirements on what they expect from uncertainty characterization in terms of geographic scope (i.e. global vs. country), type of biomass estimate needed (i.e. total or average per country or forest type), and the uncertainty measure required. Such user-targeted uncertainty characterization is essentially lacking from all large-area biomass mapping products (Böttcher et al. 2017).

\subsection{Summary and Recommendations}

The availability of new space-based data targeted at forest biomass mapping can be a game changer in terms of the level of detail and uncertainty that will become available for monitoring applications in the short term. At the same time, there have never been as many, and as explicit requests from environmental policy and resource management for quality biomass data. The question then is whether such novel data sources will also be a game changer when it comes to filling the existing data and information gaps on forest biomass for these applications. In light of the assessment of user needs here, we structure our recommendations in two main blocks, one related to the user engagement, and one for a coordinated and collaborative data provision process.

\subsubsection{Enhancing User Engagement}

There is a need to regularly gather, synthesize, and communicate user requirements of forest biomass data and space-based AGB data products. Products which better meet user needs will support forest monitoring and wider land use management applications and improve environmental policy to enable countries to help meet international climate and sustainable goals. There is no doubt that the advent of new space-based biomass missions will significantly improve the spatially and timely provision of forest biomass data worldwide in future. While research and investments in biomass monitoring technology advance, there is still little information on how it can be leveraged through the value chain of land use planning, enforcement, and policy making to improve outcomes for forests and sustainable development. The greatest advancements in forest monitoring technology often happen in agencies, laboratories, companies, or institutions in the developed world, without appropriate guidance and best practices which guide users (in particular those in developing countries) to adopt and use this technology. Consideration of institutional and financial requirements to scale, operationalize, and maintain the new technology in the context of specific applications should be undertaken and be an essential part of preparatory activities.

Further effort is required to stimulate uptake of biomass data by key stakeholders. While the integration of biomass mapping products in climate and vegetation models is already progressing (i.e. ESA Biomass CCI: http://cci.esa.int/), there has been little progress in demonstrating how biomass mapping from space can be integrated in national forest monitoring and national GHG inventories efforts. International institutions and organizations (such as IPCC, The Food and Agriculture Organization of the United Nations (FAO), The Global Forest Observations Initiative (GFOI), Global Observation for Forest Cover and Land Dynamics (GOFC-GOLD), Committee on Earth Observation Satellites (CEOS)) should stimulate and implement demonstration activities that then can lead to experiences and improved guidance, training materials, and capacity building efforts. Once there are 
successful demonstrations with users, it becomes much more straightforward to include them in ongoing capacity development processes. The 2019 refinement of the 2006 IPCC $\mathrm{GL}$ is expected to provide some initial guidance.

Biomass maps should be developed as a co-creation of both producers and users. Particular focus is needed to match estimates from biomass maps produced using space data with field-based biomass estimates and to harmonize these biomass estimates based on national definitions. The plot size of the data should also be considered since, for example, sub-national statistics or approximated geolocation of small (i.e. $0.1 \mathrm{ha}$ ) plots are not suitable for direct comparison and integration with space-based data. This requires a sustained dialogue and collaboration between the remote sensing community and the national forest inventory institutions, which is essential to combine, integrate, and reconcile biomass estimates obtained with different approaches (e.g., sample-based vs. model-based or mapping approach) and driven by different data sources, either field data or remotely sensed data which include space-based sources. Moreover, this dialogue has to be complemented by the implementation of data sharing policies that allow the access of these field-based datasets to users in general and specifically the remote sensing community, and allows in turn access to the national forest inventory institutions of remotely sensed data.

Uncertainty information is required by all stakeholders interested in using biomass maps (Romijn et al. 2018). While the data producing community aims to provide uncertainty estimates [i.e. through the CEOS WGCV efforts (Duncanson et al. 2019)], it is important to note that different applications have specific requirements on what they expect from biomass and uncertainty characterization in terms of:

- Geographic scope which ranges from global scale (i.e. for use in climate and vegetation models) or national level estimates since it is most relevant to country GHG inventories;

- The final biomass estimate needed by the users that can be the total or average biomass per country or forest type or a unit-specific value;

- The uncertainty estimates required, which can include relative and absolute systematic deviation and confidence interval or RMSE. They can be provided for the overall estimate or by biomass class/range;

- Whether a biomass estimate is needed for one time (i.e. one year) or for multiple years, and whether it includes the estimation of biomass changes;

- Compliance with IPCC good practice guidelines: (1) "neither over- nor underestimates so far as can be judged," and (2) "uncertainties are reduced as far as is practicable" (IPCC 2006).

This suggests that one biomass product and uncertainty characterization approach will not work for all users - so any effort of assessing biomass products should be co-developed by both producers and users. Often user organizations have their own forest and biomass data that they would like to integrate with biomass map data. Such efforts are, thus, not only aiming at the technical credibility of a biomass map product but also at creating ownership and saliency that are often most important for ensuring user uptake. For example, a biomass map can only become part of IPCC Tier 2 or Tier 3 emission estimation if integrated with field data acquired in the country. It is also often the user alone that can fully judge what implications estimated biomass and uncertainties have on their application. This information can be fed back to the producer on where to improve.

An increasing democratization of forest information can bring about a transformation in the forest sector because it will be easier to hold stakeholders (i.e. a state or the private 
sector) accountable for their commitments, like those related to REDD+ (Böttcher et al. 2017). Enhancing transparency is one fundamental step to make the bottom-up nature of the Paris Climate Agreement work in practice, and to facilitate open exchange of data and information, and more participatory monitoring and impact assessments involving the private sector, civil society and government agencies (Romijn et al. 2018). The opensource nature of many space-based data and products is leading the way, and this should be expanded to include other forest-related data sources. National Forest Agencies and international partners should develop protocols/agreement to make more accessible field plot data with precise geolocation to the research communities.

\subsubsection{Promoting Collaborative and Sustained Data Provision}

There is a need for international forest monitoring and data coordination groups (GFOI, GOFC-GOLD, and CEOS) to represent the needs of the data users and encourage data providers/programme funding organizations to work collaboratively to provide complementary, relevant, transparent, and validated biomass data and information.

Although the mission of space-based data providers is to provide stand-alone information on biomass, and there have been some advances in terms of data sharing (Albinet et al. 2019; Duncanson et al. 2019), further collaborations are needed. Different maps which are produced independently can cause confusion, and guidance is needed if the user is to adopt the appropriate map(s). In the previous section, we have already outlined the need to work with the user from the beginning. Such a partnership, however, requires a coordinated and collaborative data provision process to be successful. The various biomass-focussed space missions (see Fig. 1) have been thus far planned individually, but the one sensor/one map approach will not be the best solution for many of the applications we have presented here. The actual strength of these missions, which has not been fully exploited, is in their combination to increase accuracy, detail, and geographic coverage for biomass estimation, and to develop an increasingly longer time series that is certain and consistent enough to track biomass changes. Space agencies and organizations providing such data are encouraged to take action for an integrated suite of products taking advantage of having multiple measurements (radar, lidar) and creating consistent time series from multiple sensors. Historical data sources used for biomass mapping to expand existing time series should also be considered in this integrated suite, to aim for the timely delivery of new biomass and biomass change data. To achieve this, an increasing investment and collaboration in R\&D that looks into the combined potential of these missions is needed to advance the technical underpinnings and to transition from viable prototypes to operational systems within a timeframe consistent with ambitious targets set by policy frameworks.

The coordination and collaboration activities advocated here can only work if the space-based data sources are available, free, and open. At the time of writing, all missions described in Fig. 1, have an open data policy. Previous open data space missions, such as the Landsat program and the EU/ESA Copernicus missions, have demonstrated the tremendous value of freely available earth observation data for international and national environmental policy and management applications.

Almost, all of the upcoming space-based biomass mapping efforts are planned as oneoff research missions. We encourage taking steps now to operationalize biomass maps 
produced using space data (e.g. as part of EU Copernicus programme) building upon the experiences and progress made for ensuring seamless continuity and consistency of biomass mapping from space after currently planned missions end. A long-term vision for data availability is necessary for all users needing sustained observation of biomass changes (i.e. for climate users and reporting of the SDGs).

Any biomass maps produced from space data need to be underpinned by adequate field reference data for calibration and validation. In general, any calibration/validation has to rely on a coordinated effort to provide consistent protocols, and to collect and share reference data. Space agencies often have limitations in supporting large in situ data collection efforts for forest biomass. There is need to find mechanisms to increase support and partnerships with forest plot networks and implementing agencies that both can provide reference data that covers a range of forest types and disturbance regimes worldwide (see Phillips et al. 2019). Field surveys need to be planned to allow for better integration with space-based data (Næsset et al. 2015), in particular with NFI data that tend to use small plots, and are often not acquired with space-data integration in mind.

High-quality field data are needed for both calibration and validation, and the requirements for each can vary. Calibration data should be able to provide enough detail in order to allow the inter-comparison and inter-calibration of multi-source space-based data (i.e. from various radar wavelengths and lidar). Such data can increasingly be provided from terrestrial laser scanning (Disney et al. 2019) and lidar-based drone measurements (Kellner et al. 2019), including a comprehensive error analysis (McRoberts et al. 2019). Reference data for product validation should be able to support uncertainty analysis targeted for specific user needs. The product validation procedures by CEOS (Duncanson et al. 2019) are important but tend to focus on the producer perspective. The engagement with different users is essential in product uncertainty analysis (see Phillips et al. 2019).

In summary, the key challenge is to avoid a widening gap between what is evolving and demonstrated in research and in the context of space-based missions, and the diverse demands of users, particularly in terms of the need for operational systems. This can only be achieved through a long-term collaborative effort among producers and users. Such efforts are currently most advanced for climate-related biomass mapping, which can lead the way to advanced guidance and practices for the use of forest biomass monitoring data outside of climate applications. Further work should particularly look into how new biomass monitoring technologies can be integrated in the processes and institutions of land use planning, enforcement, and policy making to achieve forest and climate goals.

Acknowledgements This research has been funded by the European Space Agency (ESA) as part of the CCI Biomass project of the Climate Change Initiative (CCI) (ESA ESRIN/Contract No. 4000123662), and also by FAO, GFOI, GOFC-GOLD, and Wageningen University. We thank those involved in the EC supported H2020 REDD+Copernicus project and those who contributed to GFOI Expert Workshops (www. gfoi.org/rd). M.J. Sanz was supported by the Spanish Government through María de Maeztu excellence accreditation MDM-2017-0714.

OpenAccess This article is distributed under the terms of the Creative Commons Attribution 4.0 International License (http://creativecommons.org/licenses/by/4.0/), which permits unrestricted use, distribution, and reproduction in any medium, provided you give appropriate credit to the original author(s) and the source, provide a link to the Creative Commons license, and indicate if changes were made. 


\section{References}

Albinet C, Whitehurst AS, Jewell LA, et al (2019) A joint ESA-NASA multim-mission algorithm and analysis platform for BIOMASS, NISAR and GEDI. Surv Geophys (In review)

Asner GP, Clark JK, Mascaro J, Garc GAG (2011) High-resolution mapping of forest carbon stocks in the Colombian Amazon. Biogeosciences 9(7):2683-2696. https://doi.org/10.1186/1750-0680-6-7

Avitabile V, Herold M, Henry M, Schmullius C (2011) Mapping biomass with remote sensing: a comparison of methods for the case study of Uganda. Carbon Balance Manag 6:1-14. https://doi. org/10.1186/1750-0680-6-7

Avitabile V, Herold M, Heuvelink GBM et al (2016) An integrated pan-tropical biomass map using multiple reference datasets. Glob Change Biol 22:1406-1420. https://doi.org/10.1111/gcb.13139

Baccini A, Goetz SJ, Walker WS et al (2012) Estimated carbon dioxide emissions from tropical deforestation improved by carbon-density maps. Nat Clim Change 2:182-185. https://doi.org/10.1038/nclim ate 1354

Baccini A, Walker W, Carvalho L et al (2017) Tropical forests are a net carbon source based on aboveground measurements of gain and loss. Science 358:230-234. https://doi.org/10.1126/science.aam5962

Baede A, van der Linden P, Verbruggen A (2007) Annex to IPCC fourth assessment report. Switzerland, Geneva

Batjes NH (1996) Total carbon and nitrogen in the soils of the world. Eur J Soil Sci 47:151-163

Böttcher H, Herrmann LM, Herold M, et al (2017) Independent Monitoring: Building trust and consensus around GHG data for increased accountability of mitigation in the land use sector

Carter S, Arts B, Giller KE et al (2018a) Climate-smart land use requires local solutions, transdisciplinary research, policy coherence and transparency. Carbon Manag. https://doi.org/10.1080/17583 004.2018.1457907

Carter S, Herold M, Avitabile V et al (2018b) Agriculture-driven deforestation in the tropics from 19902015: emissions, trends and uncertainties. Environ Res Lett 13:014002. https://doi.org/10.1088/17489326/aa9ea4

Disney MI, Burt A, Calders K, et al (2019) Innovations in ground and airborne technologies as reference and for training and validation: terrestrial laser scanning (TLS). Surv Geophys (In review)

Duncanson L, Armston J, Disney M, et al (2019) The importance of global land product validation: towards a standardized protocol for aboveground biomass. Surv Geophys (In review)

Ellison D, Morris CE, Locatelli B et al (2017) Trees, forests and water: cool insights for a hot world. Glob Environ Change 43:51-61. https://doi.org/10.1016/j.gloenvcha.2017.01.002

FAO (2015) FRA 2015 terms and definitions. Rome, Italy

GCOS (2010) Implementation plan for the global observing system for climate change in support of the UNFCCC. WMO, IOC, UNEP, ICS, Geneva, Switzerland

GCOS (2015) Staus of the global observing system for climate. Full report. GCOS-195. World Meteorological Organization, Geneva, Switzerland

GCOS (2016) The global observing system for climate: implementation needs. GCOS-200. World Meteorological Organization, Geneva, Switzerland

GFOI (2016) Integration of remote-sensing and ground-based observations for estimation of emissions and removals of greenhouse gases in forests: methods and guidance from the global forest observations initiative

GlobBiomass (2017) Due GlobBiomass final report

Goetz SJ, Baccini A, Laporte NT et al (2009) Mapping and monitoring carbon stocks with satellite observations: a comparison of methods. Carbon Balance Manag 4:2. https://doi. org/10.1186/1750-0680-4-2

GOFC-GOLD (2016) A sourcebook of methods and procedures for monitoring and reporting anthropogenic greenhouse gas emissions and removals associated with deforestation, gains and losses of carbon stocks in forests remaining forests, and forestation report version. COP22-1

Griscom BW, Adams J, Ellis PW et al (2017) Natural climate solutions. PNAS 114:11645-11650. https ://doi.org/10.1073/pnas.1710465114

Haberl H, Erb KH, Krausmann F et al (2007) Quantifying and mapping the human appropriation of net primary production in earth's terrestrial ecosystems. PNAS 104:12942-12947. https://doi. org/10.1073/pnas.0704243104

Hansen MC, Krylov A, Tyukavina A et al (2016) Humid tropical forest disturbance alerts using landsat data. Environ Res Lett 11:34008. https://doi.org/10.1088/1748-9326/11/3/034008

Harris NL, Brown S, Hagen SC et al (2012) Baseline map of carbon emissions from deforestation in tropical regions. Science 336:1573-1576. https://doi.org/10.1126/science. 1217962 
Hermans-Neumann K, Gerstner K, Geijzendorffer IR et al (2016) Why do forest products become less available? A pan-tropical comparison of drivers of forest- resource degradation. Environ Res Lett 11:125010. https://doi.org/10.1088/1748-9326/11/12/125010

Herold M, Johns T (2007) Linking requirements with capabilities for deforestation monitoring in the context of the UNFCCC-REDD process. Environ Res Lett 2:045025. https://doi.org/10.1088/17489326/2/4/045025

Houghton RA, Hall F, Goetz SJ (2009) Importance of biomass in the global carbon cycle. J Geophys Res 114:G00E03. https://doi.org/10.1029/2009JG000935

IPCC (2003) Good practice guidance for land use, land use change and forestry. Kanagawa, Japan

IPCC (2006) 2006 IPCC guidelines for national greenhouse gas inventories. In: Eggleston HS, Buendia L, Miwa K, Ngara T, Tanabe K (eds) National greenhouse gas inventories programme. IGES, Japan

Irlam L (2017) Global costs of carbon capture and storage-2017 update. Melbourne, Australia

Kellner JR, Armston JD, Birrer M, et al (2019) New opportunities for forest remote sensing through ultra-high-density drone lidar. Surv Geophys (In review)

Kumar L, Mutanga O (2017) Remote sensing of above-ground biomass. Remote Sens 9:1-8. https://doi. org/10.3390/rs9090935

Le Quéré C, Moriarty R, Andrew RM et al (2015) Global carbon budget 2015. Earth Syst Sci Data 7:349-396. https://doi.org/10.5194/essd-7-349-2015

Lorenz R, Pitman AJ (2014) Effect of land-atmosphere coupling strength on impacts from Amazonian deforestation. Geophys Res Lett 41:5987-5995. https://doi.org/10.1002/2014GL061017

Lucas RM, Mitchell AL, Armston J (2015) Measurement of forest above-ground biomass using active and passive remote sensing at large (subnational to global) scales. Curr For Rep 1:162-177. https:// doi.org/10.1007/s40725-015-0021-9

McRoberts R, Næsset E, Liknes GC, Chen Q, Walters BF, Saatchi S, Herold M (2019) Using a finer resolution biomass map to assess the accuracy of a regional map-based estimate of forest biomass. Surv Geophys. https://doi.org/10.1007/s10712-019-09507-1

Mitchell AL, Rosenqvist A, Mora B (2017) Current remote sensing approaches to monitoring forest degradation in support of countries measurement, reporting and verification (MRV) systems for REDD+. Carbon Balance Manag 12:1-22. https://doi.org/10.1186/s13021-017-0078-9

Næsset E, Bollandsås OM, Gobakken T et al (2013) Model-assisted estimation of change in forest biomass over an 11 year period in a sample survey supported by airborne LiDAR: a case study with post-stratification to provide "activity data". Remote Sens Environ 128:299-314. https://doi. org/10.1016/j.rse.2012.10.008

Næsset E, Bollandsås OM, Gobakken T et al (2015) The effects of field plot size on model-assisted estimation of aboveground biomass change using multitemporal interferometric SAR and airborne laser scanning data. Remote Sens Environ 168:252-264. https://doi.org/10.1016/j.rse.2015.07.002

Ochieng RM, Visseren-hamakers IJ, Arts B et al (2016) Institutional effectiveness of REDD + MRV: countries progress in implementing technical guidelines and good governance requirements. Environ Sci Policy 61:42-52. https://doi.org/10.1016/j.envsci.2016.03.018

Phillips OL, Sullivan MJ, Baker TR, et al (2019) Species matter: multi-scalar impacts of wood density on tropical forest biomass. Surv Geophys (In review)

Prentice IC, Farquhar GD, Fasham MJR et al (2001) The carbon cycle and atmospheric carbon dioxide. In: Houghton JT, Ding Y, Griggs DJ et al (eds) Climate change 2001: the scientific basis. Contribution of Working Group I to the third assessment report of the intergovernmental panel on climate change. Cambridge University Press, Cambridge

Romijn E, Herold M, Kooistra L et al (2012) Assessing capacities of non-annex I countries for national forest monitoring in the context of REDD+. Environ Sci Policy 19-20:33-48. https://doi.org/10.1016/j. envsci.2012.01.005

Romijn E, Lantican CB, Herold M et al (2015) Assessing change in national forest monitoring capacities of 99 tropical countries. For Ecol Manag 352:109-123. https://doi.org/10.1016/j.foreco.2015.06.003

Romijn E, Herold M, Mora B, et al (2016) Monitoring progress towards sustainable development goals the role of land monitoring. http://www.gofcgold.wur.nl/documents/newsletter/Sustainable_Developmen t_Goals-infobrief.pdf. Accessed 11 Dec 2018

Romijn E, De Sy V, Herold M et al (2018) Independent data for transparent monitoring of greenhouse gas emissions from the land use sector: what do stakeholders think and need? Environ Sci Policy 85:101112. https://doi.org/10.1016/j.envsci.2018.03.016

Saatchi SS, Harris NL, Brown S et al (2011) Benchmark map of forest carbon stocks in tropical regions across three continents. Proc Natl Acad Sci USA 108:9899-9904. https://doi.org/10.1073/pnas.10195 76108

Stehman S (2009) Sampling designs for accuracy assessment of land cover. J Remote Sens 30:5243-5272 
Tompo E, Gschwantner T, Lawrence M, McRoberts R (2010) National forest inventories. Pathways for common reporting. Springer, Berlin

Turnhout E, Gupta A, Weatherley-Singh J, Vijge MJ, De Koning J, Visseren-Hamakers IJ, Herold M, Lederer M (2017) Envisioning REDD+ in a post-Paris era: between evolving expectations and current practice. Wiley Interdiscip Rev Clim Change 8(1):e425

UN (2016) UN sustainable development goals. https://sustainabledevelopment.un.org/?menu=1300. Accessed 22 Dec 2016

UN (2017) Revised list of global sustainable development goal indicators. Report of the inter-agency and expert group on sustainable development goal indicators (E/CN.3/2017/2), Annex III. 1-26

UNFCCC (2003) Report of the conference of the parties on its eighth session: 17/CP.8. New Delhi, India

UNFCCC (2015) The Paris agreement FCCC/CP/2015/L.9/Rev.1. Paris, France

WMO (2018) Essential climate variables: global climate observing system. https://gcos.wmo.int/en/essen tial-climate-variables

Zomer RJ, Neufeldt H, Xu J et al (2016) Global tree cover and biomass carbon on agricultural land: the contribution of agroforestry to global and national carbon budgets. Sci Rep 6:29987. https://doi. org/10.1038/srep29987

Publisher's Note Springer Nature remains neutral with regard to jurisdictional claims in published maps and institutional affiliations.

\section{Affiliations}

Martin Herold ${ }^{1} \cdot$ Sarah Carter $^{1}$ (D) . Valerio Avitabile ${ }^{2}$. Andrés B. Espejo ${ }^{3}$. Inge Jonckheere ${ }^{4} \cdot$ Richard Lucas $^{5,6} \cdot$ Ronald E. McRoberts $^{7} \cdot$ Erik Næsset $^{8}$. Joanne Nightingale ${ }^{9} \cdot$ Rachael Petersen $^{10}$. Johannes Reiche ${ }^{1}$ (D) Erika Romijn ${ }^{1}$. Ake Rosenqvist $^{11}$ - Danaë M. A. Rozendaal ${ }^{1}$. Frank Martin Seifert ${ }^{12} \cdot$ María J. Sanz $^{13}$. Veronique De Sy ${ }^{1}$

\section{Sarah Carter}

sarah.carter@wur.nl

1 Laboratory of Geo-Information Science and Remote Sensing, Wageningen University and Research, Droevendaalsesteeg 3, 6708 PB Wageningen, The Netherlands

2 Joint Research Centre, European Commission, Via E. Fermi 2749, 21027 Ispra, Italy

3 Climate Change Group, The World Bank, 1818 H Street, NW, Washington, DC 20433, USA

4 Food and Agriculture Organization of the United Nations, UN-REDD Programme, REDD+ Team / NFM Group, Viale delle Terme di Caracalla, 00193 Rome, Italy

5 Earth Observation and Ecosystem Dynamics Research Group, Department of Geography and Earth Sciences (DGES), Aberystwyth University, Aberystwyth, Ceredigion SY23 3DB, UK

6 Centre for Ecosystem Science, School of Biological Earth and Environmental Sciences (BEES), The University of New South Wales, High Street, Kensington, NSW 2052, Australia

7 Northern Research Station, U.S. Forest Service, Saint Paul, MN 55108, USA

8 Faculty of Environmental Sciences and Natural Resource Management, Norwegian University of Life Sciences, P.O. Box 5003, 1432 Ås, Norway

9 National Physical Laboratory, Hampton Road, Teddington, Middlesex TW11 0LW, UK

10 World Resources Institute, Washington, DC 20002, USA

11 Solo Earth Observation (soloEO), Tokyo 104-0054, Japan

12 ESA-ESRIN, Via Galileo Galilei, Frascati, Italy

13 BC3 Basque Centre for Climate Change, Sede Building 1, 1st Floor, Scientific Campus, University of the Basque Country, 48940 Leioa, Spain 